\title{
Critérios de leitura de manuscritos: em busca de lições fidedignas
}

Phablo Roberto Marchis Fachin*

RESUMO: Este artigo tem como objetivo propor uma discussão sobre a importância da utilização de critérios de leitura de manuscritos como procedimento indispensável para a produção de lições fidedignas. Entendidos aqui como aparato indispensável para o reconhecimento e distinção dos caracteres gráficos de cada texto, são necessários para a eliminação de pendências e, consequentemente, para o alcance de uma leitura sem oscilações. Está dividido em duas partes. Na primeira, contextualiza-se, muito brevemente, o momento porque passam os trabalhos filológicos e os problemas a serem enfrentados, demonstrando, por meio de exemplos de edições realizadas por importantes pesquisadores, as mudanças ocorridas na forma de se editar documentos. Na segunda parte, trata-se propriamente da importância da utilização de critérios de leitura e como isso se daria na prática, por meio de exemplos retirados de manuscritos do século XVIII.

PALAVRAS-CHAVE: Filologia; edição de manuscritos; critérios de leitura; história da Língua Portuguesa.

\section{Introdução}

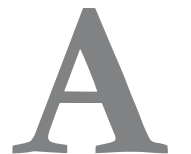

Filologia portuguesa passa por um momento muito produtivo no que diz respeito aos trabalhos de edição voltados para a conservação do estado de língua de documentos manuscritos. Após um período de oscilação entre critérios, com diferentes graus de intervenção do editor, observam-se atitudes semelhantes quanto às normas de transcrição e à tentativa de conservar as características da escrita dos documentos. Se por um lado isso tem como conseqüência a ampliação de corpora para estudos sobre a História da Língua Portuguesa; por outro, amplia-se tam-

\footnotetext{
Doutorando do Programa de Pós-Graduação em Filologia e Língua Portuguesa da Uni-
} versidade de São Paulo - phablo@hotmail.com. 
bém a exigência em relação à fidedignidade das edições produzidas, pois não é raro ainda encontrar-se lição comprometida por falta de rigor.

Levando-se tal fato em consideração, este artigo tem como objetivo propor uma discussão sobre a importância da utilização de critérios de leitura de manuscritos como procedimento indispensável para a produção de lições fidedignas. Entendidos aqui como aparato indispensável para o reconhecimento e distinção dos caracteres gráficos de cada texto, são necessários para a eliminação de pendências e, conseqüentemente, para o alcance de uma leitura sem oscilações. Baseia-se no fato de que o filólogo realiza seu trabalho com cientificismo ao estudar os documentos com a intenção de fazer com que o resultado de sua tarefa reflita fielmente o texto. Além disso, para que possa ser verificado por outros pesquisadores, divulga todas as etapas que o levou a determinado resultado. Segundo Melo (1971, p.22), um dos requisitos da crítica.

O trabalho está dividido em duas partes. Na primeira, contextualiza-se, muito brevemente, o momento porque passam os trabalhos filológicos e os problemas a serem enfrentados, demonstrando, por meio de exemplos de edições realizadas por importantes pesquisadores, as mudanças ocorridas na forma de se editar documentos. Na segunda parte, trata-se propriamente da importância da utilização de critérios de leitura e como isso se daria na prática, por meio de exemplos retirados de manuscritos do século XVIII.

Apesar da apresentação de exemplos de edições críticas de documentos antigos, voltadas à difusão do texto para um número amplo de leitores, por isso com intervenções constantes do editor, a preocupação deste trabalho é com a fidedignidade das edições produzidas com o intuito de fornecer fontes confiáveis para estudos linguísticos. Pretende-se com tal apresentação apenas demonstrar que o caráter conservador, defendido por muitos editores em suas normas, não é suficiente para garantir a reprodução das características do estado de língua dos documentos.

\section{Breve contextualização do momento porque passam os trabalhos de edição}

Ultimamente, tem aumentado muito o interesse por manuscritos coloniais e imperiais, produzidos tanto no Brasil quanto em Portugal, com o propósito de preparar edição confiável para a pesquisa em História da Língua Portuguesa e Linguística Histórica. É crescente o aumento de grupos de pesquisa de diversas universidades que trabalham com esse tipo de documentação e que têm em seus projetos o objetivo de produzir lição confiável para 
estudos de língua escrita. Esse interesse é consequência, por um lado, da escassez de documentos editados e, por outro, do número reduzido de edições existentes preparadas rigorosamente para estudos linguísticos. A afirmação de Melo (1971, p.41), apesar do tempo transcorrido, ainda tem relevância:

Dada a importância dos textos para a Filologia e dada a nossa triste indigência nessa matéria, abre-se um imenso e urgente campo de trabalho a pedir competências e boa vontade: o estabelecimento rigoroso de textos brasileiros e portugueses, antigos e modernos.

Boléo (1946), Silva Neto (1956) e Cambraia (1999) são exemplos de autores que trataram dessa questão. O primeiro (Boléo, 1946, p. 77), ao fornecer algumas indicações práticas sobre a técnica do trabalho de investigação filológica, atenta para a necessidade da escolha de boas edicões, ${ }^{1}$ pois os erros são frequentes e podem originar "explicações linguísticas injustificadas".

Silva Neto (1956, p.27-33) levanta os problemas de lição de textos medievais, sistematizando-os em a) erros devidos à má compreensão de letras; b) erros devidos a desconhecimentos de fatos linguísticos; c) erros devidos à ignorância de siglas e abreviaturas; d) saltos-bordões; e) erros devidos à má separação das sílabas.

Cambraia (1999, p.13-16) relaciona o problema da escolha de fontes à sua escassez, a distorções apresentadas em razão do processo de transmissão e à existência de edições impróprias por natureza para estudos linguísticos, enfatizando a necessidade de o próprio pesquisador realizar a edição que será a base de seus estudos.

Megale (2001), Cambraia (2001) e Toledo Neto (2001), ao analisarem transcrições de manuscritos, também se depararam com lições impróprias para estudos linguísticos. Segundo os autores, a finalidade histórica da edição, o fato de que nem sempre o próprio editor seguia as suas normas, os erros de leitura e as incongruências nos critérios de transcrição contribuíram para o comprometimento desses trabalhos. O objetivo "justificaria os critérios adotados, tais como a separação de palavras escritas juntamente, não marcação da mudança de linha, não desenvolvimento de abreviaturas, modernização do emprego de maiúsculas e minúsculas" (Cambraia, 2001, p. 531).

Para Megale (2001, p.535-7), além dos erros de leitura, observa-se ainda que há outras incongruências nos critérios de edição, não havendo em nenhum dos tópicos interesse em ser exaustivo. Além dos problemas citados

\footnotetext{
Itálico do autor.
} 
no parágrafo anterior, traz também a questão da introdução de hífen, ausente nos manuscritos analisados, modernização da acentuação, da marca de nasalidade ão por ã̃, alteração na pontuação original, entre outros casos.

Toledo Neto (2001, p. 546) conclui que

\begin{abstract}
a comparação entre manuscritos e transcrição demonstra, portanto, que um documento que vise a fornecer subsídios para estudos lingüísticos deve obedecer a critérios previamente estabelecidos, os quais sejam observados rigorosamente, de modo que não possibilitem oscilação nas leituras apresentadas, reproduzindo minuciosamente as características do original.
\end{abstract}

\title{
3. Dlferentes Critérios Para Diferentes Objetivos
}

A fidedignidade de uma edição ao original e a conservação de seu estado de língua podem ser garantidas pela utilização de normas de transcrição e critérios de leitura. Elaborados e seguidos com rigor, tais preceitos, porém, não são criados arbitrariamente, são frutos da experiência de leitura de uma gama de textos. Coerentes, portanto, ao tipo de documentação e ao objetivo com que se trabalha, assegurando, assim, a cientificidade da pesquisa filológica.

Castro e Ramos (1986), para falarem sobre os diferentes sistemas de transcrição e de publicação dos documentos e textos medievais e modernos que se têm verificado, correram mais de meia centena de normas, escolhendo as que lhes pareceram representativas das várias tendências que esperavam encontrar. Nessa busca, encontraram atitudes que vão desde a conservação quase radical das grafias do testemunho de base até a sua não menos radical modernização, passando por muitos estágios intermediários, que se podem dispor gradativamente.

Segundo Picchio (1979, p. 251), que também tratou dessa questão, pesquisadores que defendem a tendência conservadora justificam que um texto vale como realidade histórica, simultaneamente fonética e gráfica; qualquer alteração é um arbítrio injustificado e injustificável. Já os que defendem a tendência modernizadora indagam que não se deve esquecer que a obra se destina antes do mais à leitura, e que essa leitura deve ser facilitada, e não dificultada pela convenção gráfica.

A utilização de determinada norma de transcrição depende, portanto, do objetivo da edição, pois a preocupação com valores literários, históricos ou lingüísticos influencia o nível de intervenção do editor no original. Por isso, para cada intenção, uma norma diferente. Daí tantos casos de critérios que trazem em seus tópicos interferências no estado de língua dos documentos 
com a intenção de atender a um público maior, principalmente quando se tratava de textos literários.

Fala-se, nesse caso, em edição crítica. Como afirma Vasconcelos (1928, p.3140), "numa edição crítica procura-se, tanto quanto possível, apresentar ao leitor a obra tal qual o autor a redigiu". Realizada por diversos motivos, entre eles, a perda do original, a corrupção do texto no decorrer de sua transmissão e a ocorrência de lacunas devido à falta de conservação, possibilita ao editor fazer intervenções a fim de que se eliminem as obscuridades e torne a obra acessível a todos.

Esse tipo de trabalho, pertencente à crítica textual, tem seu campo de atuação muito amplo, principalmente em relação às edições críticas de textos antigos. Como exemplo, pode-se citar as cantigas d'escarnho e de mal dizer dos cancioneiros medievais galego-portugueses por Lapa (1965), Crônica Geral de Espanha, de 1344, por Lindley Cintra (1951) e as poesias de Sá de Miranda por Michaëlis de Vasconcelos (1885).

$\mathrm{Na}$ tentativa de restituir os segmentos originais eliminados, filólogos de outras épocas davam mais importância a valores literários e históricos do que a lingǘsticos. Como conseqüência, entre as normas seguidas pelos editores, estava presente a uniformização de determinados aspectos gráficos, ou seja, na maioria dos casos, não estava incluído o oferecimento de fontes voltadas para a pesquisa de língua escrita, o que contribuía para o apagamento de marcas linguísticas. Mesmo nas edições em que se defendia a conservação das características do original, havia algum tipo de interferência. A afirmação de Castro e Ramos (1986, p.105) confirma tal fato.

Fidelidade, respeito religioso, recusa de adulterar o texto, intervenção parcimoniosa - são as formas repetidas por todas as vozes, é o discurso de base comum a todos os editores. Discurso que, no entanto, ao ser emparelhado com os comportamentos efectivos de cada editor nas suas edições, revela apreciáveis variações na distância que vai da palavra à coisa e na intensidade do gesto de cada um deles.

A afirmação de Picchio (1979, p.252) se insere bem nesse contexto: "nos últimos trinta anos, as normas seguidas na edição de textos arcaicos conheceram todas as gradações, desde a fidelidade infiel à fiel infidelidade". Segundo Castro e Ramos (1986, p.103), talvez seja a escola de editores americanos, desenvolvida em torno de E. B. Williams, quem produziu as edições de índole mais conservadora. Tanto nas edições diplomáticas, em que se reproduzem fielmente os caracteres gráficos do documento, quanto nas críticas, esses filólogos americanos atingiram extremos de fidelidade. Os autores ainda 
citam os exemplos de Henry Carter, com a edição diplomática do Cancioneiro da Ajuda, e Joseph Allen, com a edição crítica da Vida de Santo Aleixo.

Para a compreensão de como isso ocorria em edições de textos antigos, segue como primeiro exemplo o procedimento utilizado por Nunes (1926). ${ }^{2}$

Direi agora como procedi no meu trabalho. Dei o texto tal qual consta dos respectivos apógrafos, ou melhor, como se me afigurou dever ler-se em ambos, cotejando cantiga por cantiga; quando havia entre êles divergência, preferi as lições que me pareceram melhores; só no caso de nenhuma satisfazer e haver evidente deturpação do primitivo original, por não terem os copistas decifrado êste, é que tomei a liberdade de me afastar dêle, já lendo-o como se me afigurou teria sido a primitiva lição (1), já acrescentando ou eliminando palavras que excediam a medida regular, colocando aquelas entre colchetes, mas dando sempre à parte as lições, constantes dos manuscritos. Nestas alterações regulei-me algumas vezes pela rima, outras pelo paralelismo dos versos. Na cantiga CCLVI, verso 23, indiquei por' o valor duplo do o de ousar. Por vezes os copistas deixaram de observar a conveniente ordem na transcrição das estrofes, escrevendo num só dois versos ou viceversa; na sua separação guiei-me igualmente pela rima e número de sílabas. Ainda no caso de acrescentamento ou eliminação de palavras nem sempre procedi coerentemente, sobretudo depois que li o excelente livro de P. H. Ureña sobre La Versificación irregular en la poesía castellana; devo contudo dizer que estou convencido de que a ametria só por excepção se encontra nos Cancioneiros trovadorescos.

Da ortografia é que me permiti afastar-me um pouco, no intento apenas de a tornar mais harmónica e regular, estribado, porém, nos próprios apógrafos, que aliás se me afiguram reproduzir não a da época em que primitivamente foram escritos, mas doutra posterior, talvez, a usada no século XV. Assim o $b$ eliminei-o por completo, quer fosse inicial, quer interno, apenas o mantive em $n^{1 / 2}$ bum, na incerteza se êste vocábulo soaria nenhum, como hoje, ou nem um, que se ouve ainda ao povo; quando tinha o valor de $i$, substitui-o por esta vogal (1); em vez de $y, i$ ou $j$ e $u$, empreguei $i$ ou $j$ e $u$ ou $v$, conforme estes sinais valiam de vogal $(i, u)$ ou de consoante $(j, v)(2)$; o $n$ intervocálico rara o conservei, quando representante de ressonância nasal, e em vez dêle, servime do til, que é o sinal em tal caso usado (3); dupliquei o $s$ nas mesmas condições, sempre que tinha o valor de surdo, mas simplifiquei-o, se, inicial, tinha idêntico som (I); quando absorvido pela consoante seguinte, geralmente $I$, indiquei-o ou por apóstrofe ou, como hoje se faz, por travessão; reduzi igualmente a simples qualquer consoante que por acaso apareça dobrada, quer no princípio, quer dentro de vocábulo, caso que, excluindo naturalmente o $s$ e $r$, só se dá com o $f(2)$. A cedilha, que hoje se sotopõe ao $c$, só quando, interno e antes de $a$, o ou $u$, tem o valor de sibilante, omiti-a nos casos em que a encontrei na mesma consoante, seguida de e ou $i$; o ditongo ascendente e

2 Encontram-se como estão apresentados pelo autor, inclusive quanto à ortografia. 
tónico - io encontra-se grafado também -iu, como - us, a par de -os, isto é-, de $o$ final de palavra, seguido de $s$ em posição átona (assim se diferençam as formas átonas das tónicas dos pronomes pessoais ou sejam, por exemplo, nus, vus e nos, vos); eu preferi em geral a escrita -in e -os. Os demais sinais gráficos mantive-os: assim os dois sons do $g$, isto é, o oclusivo e o sibilante, são representados: o $1 .^{\circ}$ por $g u, o .^{\circ}$ por $g$, antes de $e$ ou $i$, ou por $j(\mathrm{I})$; o $x$ parece ter tido valor idêntico ao do ze $s$ final (2).

O procedimento utilizado por Nunes não se distanciava muito das propostas de outros pesquisadores de sua época. Por estar preocupado em fazer com que a sua edição se tornasse acessível ao maior número de leitores, não hesitou em fazer a regularização da grafia dos códices, como pode ser observado no segundo parágrafo da descrição de seus critérios, da ortografia é que me permiti afastar-me um pouco, o intento apenas de a tornar mais harmónica e regular.

Nunes (apud Castro e Ramos, 1986, p. 107), buscando facilitar a leitura, age da mesma forma ao editar a Crónica da Ordem dos Frades Menores. A explicação do autor:

como o meu intento foi tornar accessível ao maio número a sua leitura, não hesitei em fazer-lhe as alterações conducentes a êsse fim, sem contudo deixar de o reproduzir com a máxima fidelidade, respeitando escrupulosamente o seu conteúdo e ortografia afastando-me daquele só quando da sua manutenção resultava ou ininteligência do sentido ou quebra notável das leis da sintaxe.

Segue trecho de como ficou uma das cantigas editadas por Nunes (1926). Ao lado, a versão fac-similada da mesma cantiga retirada do Cancioneiro da Vaticana. Em todas as linhas da cantiga, há interferência do editor em relação ao original. Além da inserção de apóstrofe, de hífen e de pontuação, ficam marcantes a substituição do $<y>$ e do $<j>$ por $<\mathrm{i}>$, do $<\mathrm{i}>$ por $<j>$ e o desenvolvimento de abreviaturas sem a devida indicação. 
244 MARCHIS FACHIN, Phab lo Roberto. Critérios de leitura de manuscritos: em busca de lições fid ed ignas

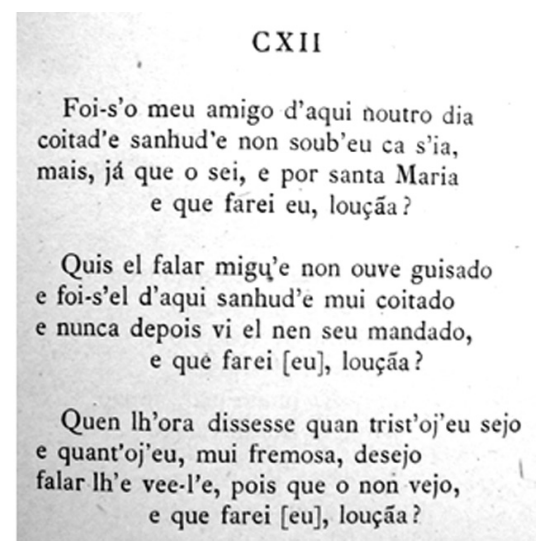

Figura 1 - “ versão de Nunes.

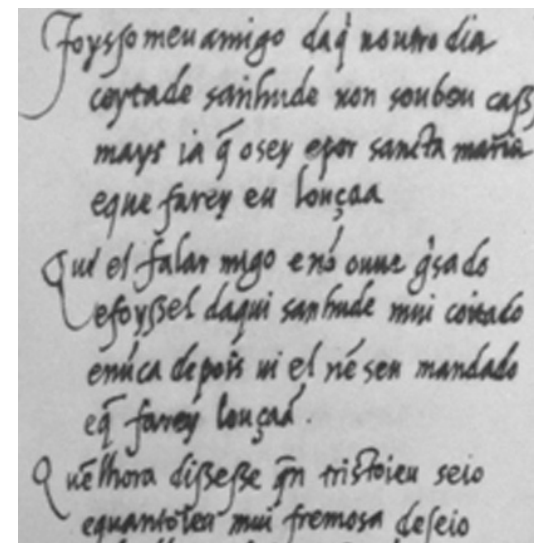

Figura 2 - " versão Cancioneiro da Vaticana.

Nunes, ao estabelecer os critérios de sua edição, cita os de Leite de Vasconcelos (1928) como exemplo a ser seguido.

Para Leite de Vasconcelos (1928, p.314-315), nos casos mais gerais, para facilitar ou amenizar a leitura, principalmente quando as edições se destinam ao geral das pessoas (ao grande público), poderiam fazer-se algumas modificações gráficas, mas de modo que a língua, tanto na pronúncia, como na maneira usual de representar os vocábulos, fique respeitada. Tal afirmação demonstra a consciência do autor sobre a importância da coerência dos critérios de transcrição ao objetivo da edição, mantendo-se sempre a intenção de conservar-se ao máximo o que o texto nos traz. No entanto, qualquer modificação que se faça durante a edição, se não corrompe o estado de língua do documento, apaga as marcas do hábito de escrita de quem o produziu, afastando-o de estudos linguísticos.

Apesar de o autor (1928, p.318), ressalvar que qualquer alteração que se faça, deva ser indicada em nota e havendo alterações gerais e extensas devam ser assinaladas em advertência preliminar, suas normas apresentam possibilidades de intervenção do editor que, além de não conservarem o estado de língua do documento, não mantêm o hábito de escrita dos escribas. O item 1 , logo abaixo, em que se defende a paragrafação, a uniformização e a modernização do uso de maiúsculas e minúsculas, é exemplo disso. Para a época, tanto essa atitude quanto a de Nunes eram aceitas sem qualquer restrição.

Esses são os critérios sugeridos por Vasconcelos (1928, p.315-319): 
1. Pontue-se o texto: paragrafe-se; ponham-se traços nos diálogos; adopte-se letra inicial maiúscula nos casos em que hoje adoptamos; substitua-se por minúscula a inicial maiúscula mal adoptada (escreva-se, por exemplo: o valor do dinheiro e não o valor Do dinheiro, grafia freqüente em manuscritos).

2. Desfaçam-se as abreviaturas, excepto por ventura as que forem sistemáticas (hoje, por exemplo, escrevemos sistematicamente "D." por "Dom", "S. or “ por "Senhor"). Escreva-se que e não q.: us ou os, conforme os casos, e não 9 (sinal muito freqüente).

3. Nasais. Quando houver oscilação, como em andã andan andam, mand $1 / 2$ manden mandem, poem põe, saom são ou saõ, adopte-se a grafia mais geral (é sabido que muitas vezes o uso do til ou do n depende de querer encurtarse um palavra para caber na respectiva linha), ou adoptem-se tôdas, porque houve tempo em que ã e $1 / 2$ soavam coo vogais nasais, e não ditongos, como hoje. em grafias como presente, comtra substitua-se $\mathrm{m}$ por $\mathrm{n}$, quando o $\mathrm{m}$ não fôr autêntco e propositado, mas devido à ignorância ou desleixo do copista.

4. Sibilantes. O S pode ser substituído por s; quando a cedilha fôr sistemática em çe e çi, deixe-se, e restitua-se quando num ou noutro caso o escriba se esqueceu de a indica. Deve, se assim está no texto, escrever-se Çamora, cetim, sossego (sessego). Grafias como cassa por casa, ese por esse poderão ser substituídas por casa e esse, com tanto que em nota ou em advertência preliminar se advirta o leitor. (315)

5. Deve transcrever-se $\mathrm{h} \sim$ ua e não huma (como se faz nos Portugaliae Mon. Hist.). A pronúncia era como $\sim \mathrm{u}$, como hoje ainda em algumas terras. Igualmente, por motivo análogo, deve transcrever-se alg $\sim$ ua, $1 \sim$ ua, com $\sim$ ua, bõa.

6. Nomes próprios. Em casos como Pedramigo, Pero Dambroa, Pay Soares, deve transcrever-se Pedr'Amigo, Pero d'Ambroa ou Dambroa (como hoje, às vezes, se escreve Dantas por d'Antas), Pay'Soares. Acêrca de Pere Estaço vid. Licções de Philologia Portuguesa, pág. 176.

7. Deverão fazer-se as correções evidentes, como lenço por lenco. Cfr. \44.

8. Deve deixar-se tudo o que, embora destoando do moderno, represente pronúncia arcaica, por exemplo Paeç, ou Paez, moderno Páes ou Páis.

9. Use-se de acento em certos casos, para evitar confusão ou errada pronúncia, e de hífen para as enclíticas: esquéce-se ou esquéce-sse, e não esquecese ou esquecesse. Poderá também acentuar-se Páeç (vid. \8).

10. As proclíticas, por exemplo, aalma, eele, oamigo, poderão separar-se, como hoje, pois que na pronúncia se unem; querendo ser mais rigoroso, poderá escrever-se a'alma, e’ele, o’amigo, como já fiz algures. Uma grafia como da foramento substitua-se por d'aforamento.

11. Y grego. Os antigos usavam-no muito, por exemplo, nos ditongos: ley, pay; deve deixar-se aí. Noutros casos poderá deixar-se ou substituir-se por i, conforme o critério do editor. Há casos em que o escriba ligava certa dignidade ao $y$, escrevendo por exemplo ygreja (há uma obra francesa medieval intitulada Ysopet, há um escritor hespanhol antigo que se assina Yepes, outro que se assina Yriart, outro Yciar, etc). (316) 
12. Poderá respeitar-se $u$ consoante e $i$ consoante, escrevendo por exemplo iá (já), com acento, para evitar $i a$. Ou poderão substituir-se por $v$ e $j$, visto que, assim como S é mera forma de $\mathrm{s}$, assim $v$ a é de $u$, e $j$ de $i$. Às vezes nos próprios textos antigos se encontra $i j$, para evitar repetição de $i$; e do século XVI há obras em que a par de $u$ consoante se escreve $j$. O $j$ vogal será substituído por $i$ (v. g. mill e vila por mjll e vila), e o $v$ vogal por $u$ (v. g. uso por vso).

13. Poderão deixar-se: ff-, rr-, ss- iniciais; 11 finais de sílaba, pois denotam pronúncia; qua-, quo, gua, guo-, em veguada, quomo, etc., pois o $u$ como que completa o $q$ e o $g$ (além disso o $u$ pode denotar pronúncia).

14. Apesar da ortografia moderna se preconizar dêste, dum, daqui, parece mais claro escrever d'êste ou d'este, d'um, d'aqui.

15. Se num texto houver omem, aver, não se adopte o $h$; mas deixe-se em hum, $b a$, he. Estando $a$ por $b a$, poderá adoptar-se $b a$; estando be por $e$ (conjunção), poderá suprimir-se o $h$, ou declarar em nota ou advertência que he significa $e$.

16. Em caso de letra geminada indevidamente, como fillosofo, ou em nogo, como $g$ por $j$, poderão respeitar-se, ou não, essas grafia; mas adoptando-se $g$, deve advertir-se em nota que $g$ vale $j$. (317)

17. Nos textos onde predomine o valor filológico ou paleográfico, seja-se mais rigoroso; mas onde predomine o valor literário, histórico, moral, scientífico, seja-se menos, porque convém que da fidelidade da reprodução não resulte para o leitor ordinário divergência grande entre a grafia, e a pronúncia dêle.

Cunha (1956), ao editar o Cancioneiro de Martin Codax, ${ }^{3}$ também utilizou princípios críticos que possibilitavam a interferência do editor nesse tipo de trabalho.

1. Eliminamos tôdas as particularidades gráficas dos códices que se não relacionam com a pronúncia das palavras, pois, como diz muito bem Alberto Chiari, "solo gli inesperti possono credere di fare una edizione critica, lasciando scrupulosamente grafie antiquate.... non sapendo distinguere ciò che è fatto puramente grafico, da non rispettarsi, da ció che è fatto propriamente fonetico e che va rispettato".

2. Desenvolvemos tôdas as abreviaturas dos códices.

$3 .^{\circ}$ De acordo com a gramática e o sentido, isolamos os vocábulos conglomerados e juntamos os elementos da mesma palavra quando desunidos.

Trata-se da primeira edição desse trabalho, pois, como afirma Spaggiari \& Perugi (2004, p.233), "Celso Cunha voltou a ocupar-se do cancioneiro de Codax, em resposta à edição de Spaggiari 1980b, com dignidade, respeito e equilíbrio". Segundo os próprios autores, "longe de reproduzir esterilmente as suas posições de 1956, chegou até a projetar uma nova edição, admitindo que podiam existir soluções diferentes em relação às escolhas por ele próprio anteriormente feitas". 
4. ${ }^{\circ}$ Suprimimos o $b$-de bi, birey e $b u$.

5. ${ }^{\circ}$ Empregamos as letras ramistas $j$ e $v$ onde se encontram $i$ ou $u$ simbolizando aquelas consoantes.

6. ${ }^{\circ}$ Ligamos por hífen os pronomes mesoclíticos às formas verbais de que dependem e também o artigo el à palavra rey.

7. Indicamos por apóstrofo a elisão vocálica, bem como a perda do $-s$ de formas verbais, assimilado ao $l$ - do artigo $l o$.

8. ${ }^{\circ}$ Conservamos aglutinadas as combinações do, eno, no e na, que já no século XIII não se separavam.

9. ${ }^{\circ}$ Usamos maiúsculas não só nos casos em que a pontuação anterior as exige, mas também no topônimo Vigo e no nome Deus.

10. ${ }^{\circ}$ Adotamos um sistemas de acentuação semelhante ao atual.

11; Pontuamos à moderna, sòbriamente, mas sem prejuízo das características tonais do enunciado.

12. ${ }^{\circ}$ Damos ao $i$ sòmente o valor de vogal, deixando ao $y$ o de semivogal. Assim, escrevemos mia, irmana, etc., mas baylava, irey, etc.

13. ${ }^{\circ}$ Resolvemos em $o$ a vogal velar reduzida em sílaba final, que também se representava por $u$.

14. ${ }^{\circ}$ Não havendo distinção quanto à nasalidade final, que ora é expressa por $m$, ora por $n$, ora por til, uniformizamo-la em $-n$, para evitar as grafias - am e em que, hoje, simbolizam respectivamente o ditongo --ãw átono e o ditongo $1 / 2 y$ (ou -ãy, em certas regiões de Portugal).

15. A nasalidade medial, indicamo-la de acôrdo com os hábitos modernos: por $m$, quando a vogal nasal antecede as consoantes $p$ e $b$, e por $n$, quando precede outras consoantes.

$16 .^{\circ}$ Escrvemos $n h$ e $l h$, conforme a lição de $B$ e $V$, e nãl $n n$ e $l l$, como está no $P V$, pela evidente vantagem daquelas grafias (de origem occitânica), introduzidas em fins do século XIII no ocidente peninsular, sôbre as últimas, não raro causadoras de ambigüidades.

17. ${ }^{\circ}$ Por constarem do aparato crítico das cantigas as variantes dos manuscritos e a justificação de nossa leitura, julgamos desnecessário indicar por colchêtes os elementes introduzidos no texto e por parênteses os que dêle foram eliminados.

Segue como ficou editada uma das cantigas de Martin Codax por Cunha. Ao lado, a versão fac-similada da mesma cantiga feita do Pergaminho Vindel. 


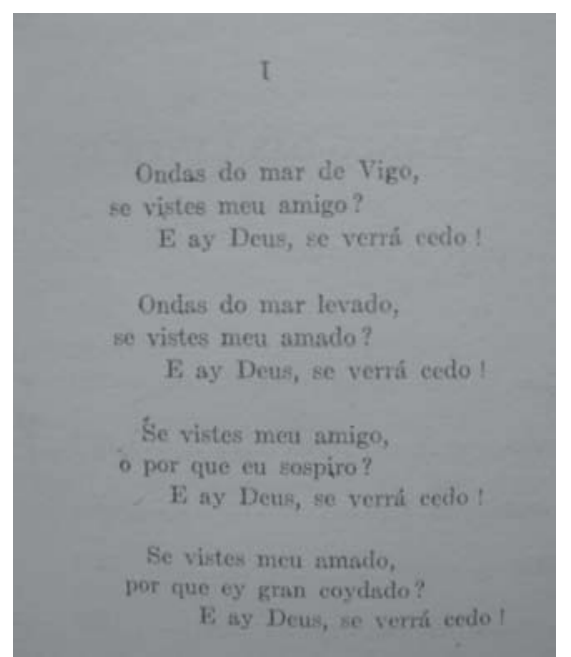

Figura 3 - "versão de Cunha.

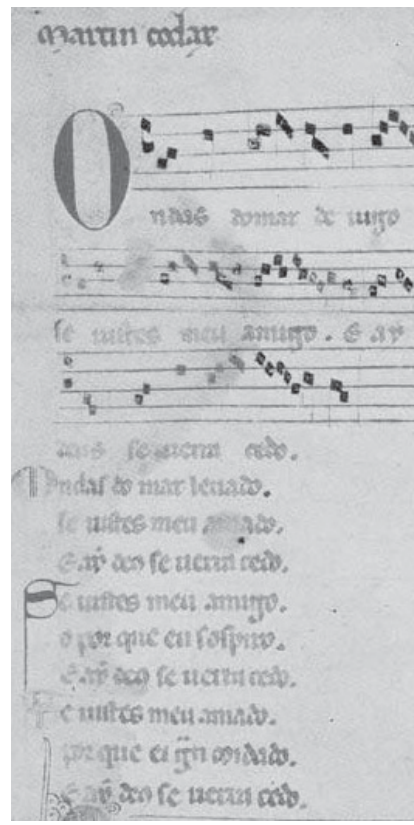

Figura 4 - " versão Pergaminho Vindel.

Desde o primeiro tópico das normas de Cunha, Eliminamos tôdas as particularidades gráficas dos códices [...], até o último, [...] julgamos desnecessário indicar por colchêtes os elementes introduzidos no texto e por parênteses os que dêle foram eliminados, percebe-se o nível altíssimo de intervenção proposto. Trata-se, na verdade, de uma atualização do estado de língua do original à época do editor. Fica claro que o critério seguido valoriza o aspecto literário e objetiva apenas tornar o texto acessível ao maior número de leitores, mesmo que para isso se interfira nas características da escrita do documento.

Michaëlis de Vasconcelos (1990/1904, p. x-xxvii) também tomou atitude regularizadora em relação aos aspectos gráficos ao fazer a edição crítica do Cancioneiro da Ajuda.

Pôsto que siga na edição crítica processos jeralmente aceitos, e os explique por miudo nas Investigaçoes, é dever meu prestar contas, tambem neste lugar, das modificações que introduzi no texto. [...] As modificações ortográficas a que submeti o texto, tendem a aussiliar a compreensão sem todavia desfigurarem o seu carácter arcáico. Sem isso, poucos portugueses o haviam de lêr. E falharia então uma das minhas principaes ambições. [...] Resta-me indicar as modificações a que submeti a escrita. Cifram-se no seguinte. 
Desenvolvo as abreviaturas, pelo modo exposto no Capítulo III das Investigaçoes. Imprimo sempre por extenso o refrã, mesmo onde nas repetições o copista escreveu apenas as primeiras palavras, ou meras iniciaes. Emprego maiúsculas não só depois de ponto, mas também nos nomes próprios, incluindo o Amor, onde me parece estar personificado, assim como Deus, e Senhor, com aplicação a Deus. Junto sílabas de palavras, onde os poetas as havaim retalhado para informar os cantores da sua distribuição musical. Separo conforme as exijéncias da gramática e do sentido, vocábulos conglomerados, quer por falta de espaço, quer propositadamente para indicar a acentuação frásica. Nestes casos deixo-os todavia conjugados por meio de sinaes diacríticos, de que logo falarei. Letras que julgo devermos acrescentar, vão entre parénteses rectangulares, jeralmente em grifo; as que na minha opinião podiam ser suprimidas para que o verso tivesse maior correcção prosódica, vão entre parénteses curvilíneos.

Pontuei com abundância, por condescendéncia com o gôsto português, e também porque creio que realmente uma boa disposição das partes do discurso equivale a um comentário, e dá mais vida e côr a versos pálidos e monótonos, de construções tão complicadas como o são ás vezes os dos poetas áulicos do séc.XIII. Emprego mesmo o sinal de interrogação e exclamação, invertido, em princípio de frase.

Com acentos e tremas, apóstrofos e hífens não fui tão pródiga, pelo menos na primeira metade do volume. Perguntas e observações do amigo que leu as provas, levaram-me então a empregar mais alguns (a contar do verso 2316).

Ponho acentos - com os valores jeneralizados de há muito, i. é agudo para vogaes abertas, circunflecso para fechadas - apenas com o fim de diferenciar palavras tónicas das átonas, gràficamente iguaes. [...].

Em algumas ligações, tão intimamente fundidas que já no século XIII nunca se efeituava a separação, não ponho sinal algum. Escrevo sempre do, dos, das; del, al (ántes de rei); eno, enos, ena, enas (respectivamente no, na), e também num, noutro, neste, naquel, assim como polo, pola, polos, polas.

O apóstrofo, emprego-o em ligações em que houve perda casual, quer de vogaes (tod'ome, menr'eu, og'eu, cuita'n, a'migo) quer de consoante (poi'-lo, Deu'-lo, matá'-lo) [...].

Quanto ao resto da escrita, não a uniformizei em absoluto. Regularizei-a apenas, cinjindo-me ás tendéncias preponderantes, simplificadoras, dos trovadores, tanto na proscrição do $b$ mudo e das letras jeminadas em princípio de dição, como na escolha de $n$ para a nasalidade, em fim de vocábulos, e $m$ no interior, ántes das explosivas $p$, $b$; e ainda no emprego de um só $s$ e $r$. Deixei subsistir as indecisões a respeito de $i$ vocálico e $y$ grego, e das jeminadas no meio dos vocábulos, por serem muito freqüentes e não causarem confusão. Modificações incisivas são apenas a introdução de $j$ e $v$, que não precisa de justificação, e a substituição de $n n, l l$ por $n h$, $l h$. Bani os símbolos $n n$, $l l$ por serem estranjeirismos anti-etimológicos, não sòmente inúteis, mas enganadores. [...] 
Segue edição de uma das cantigas do Cancioneiro da Ajuda feita por Vasconcelos (1990/1904, p. 11). Ao lado segue imagem fac-similada constante do Cancioneiro da Ajuda:

(Tr. 68).

Quen oge mayor cuita ten d'amor eno seu coraçon de quantos d'el cuitados son, Nostro Senhor the ponha i

5 conselho, se a el prouguer' atal per que lh'a tolha én.

$\mathrm{E}$ creed' ora ũa ren: ca non é outre se eu non, que mi-a tive dê-la sazon

10 que eu primeiramente vi, per bõa fé, atal molher que dá mui pouc(o) ora por én.

Mais pero, enquant' eu viver', sempre a ja mais amarei

15 d'outra cousa, e rogarei, o mais que eu poder' rogar, a Deus que el mi-a leix(e) oïr falar e mi-a leixe veer;

Figura 5 - “versão de Vasconcelos.

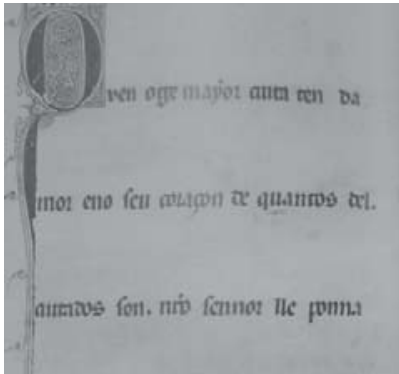

F. whiflle fesel purguer stal pere que

ILs mills ch.

Gareo oza buลa tuน

ànó couttr f́cu no.

gimua nue ritu Gron.

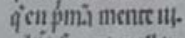

plovi fe and moller

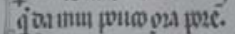

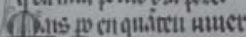

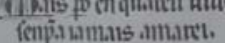

toutta wuít emgarel.

omats i cu forer mar.

. The id mulare ovic.

lievid mialcux ove.

filar:ima lete neer.

fe ocic quifer froet.

Elogo en mun fentur.

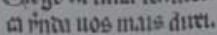

เorr manuciet aquear

cemunct is auter farnt

enes das que cat unice.

Figura 6 - " versão Cancioneiro da Ajuda.

Como os critérios dos autores mencionados neste trabalho, os que foram adotados por Michaëlis de Vasconcelos têm como princípio a adequação do estado de língua do documento ao da época da autora, dessa forma, impedindo que o resultado desse trabalho seja utilizado para estudos de língua do respectivo período. Atitude semelhante pode ser observada em muitos filólogos da época, pois esse tipo de edição, além de muito comum, era aceita por valorizar a difusão da obra. Assim, além de não conservarem o estado de língua do documento em razão da intervenção do editor, não mantêm o hábito 
de escrita dos escribas. A inserção de apóstrofo, de pontuação e a substituição dos conjuntos $<$ nn $>$ por $<$ nh $>$ e $<$ ll $>$ por $<$ lh $>$ confirmam tal fato.

Atualmente, quem objetiva estudos de língua escrita tem dado preferência a trabalhos que tenham como base edições conhecidas como semidiplomáticas, pois, além de conservarem o estado de língua da época em que os documentos foram produzidos e o hábito de escrita de seus escribas, facilitam a sua leitura ao passar os caracteres manuscritos para os tipográficos e, principalmente, desenvolver as abreviaturas e indicar os problemas decorrentes de deteriorações diversas.

A realização desse tipo de edição tem coincidido com o uso de uma documentação composta essencialmente por manuscritos não-literários, como documentos notariais e jurídicos, alvarás, autos, autuações, bilhetes, cartas, certidões, entre muitos outros, pois, por não possuírem uma preocupação demasiada com a forma, registraram diversos usos da língua muito mais representativos para estudos lingüísticos do que os literários, produzidos, na maioria das vezes, sob muito cuidado.

Os critérios de transcrição utilizados para esse tipo de edição são elaborados com a intenção de conservar o estado de língua dos manuscritos, possibilitando, menos possível, a interferência do editor. Nos casos em que houver necessidade, são respeitados procedimentos que deixem explícita a intervenção ao leitor.

O editor esclarece a trajetória de seu trabalho, desde as motivações que o levaram a escolha de tais documentos, até o critério utilizado. Tal atitude demonstra o rigor empregado na tarefa filológica e proporciona ao leitor a possibilidade de verificação do resultado. Como exemplo desse tipo de preceito, indicam-se as Normas para Transcrição de Documentos Manuscritos para a História do Português do Brasil (Cambraia, Cunha, Megale, 1999. p. 23-26), propostas durante o II Seminário para a História do Português Brasileiro, realizado em Campos do Jordão-SP, no período de 10 a 16 de maio de 1998. A comissão que as elaborou estava composta pelos seguintes pesquisadores: Heitor Megale (USP), César Nardelli Cambraia (USP), Gilvan Muller de Oliveira (UFSC), Marcelo Módolo (mestrando-USP), Permínio Ferreira (UFBa), Sílvio de Almeida Toledo Neto (USP), Tânia Lobo (UFBa) e Valdemir Klamt (UFSC). Trata-se de importante direcionamento para aqueles que pretendem trabalhar com edição de manuscritos. 
1. A transcrição será conservadora.

2. As abreviaturas, alfabéticas ou não, serão desenvolvidas, marcando-se, em itálico, as letras omitidas nas abreviaturas, obedececndo aos seguintes critérios:

a. respeitar, sempre que possível, a grafia do manuscrito, ainda que manifeste idiossincrasias ortográficas do escriba, como no caso da ocorrência "munto", que leva a abreviatura "m. to" a ser transcrita "munto";

b. no caso de variação no próprio manuscrito ou em coetâneos, a opção será a forma atual ou a mais próxima da atual, como no caso de ocorrências "Deos" e "Deus", que levam a abreviatura "D." a ser transcrita "Deus".

3. Não será estabelecida fronteira de palavras que venham escritas juntas, nem se introduzirá hífen ou apóstrofo onde não houver.

Exemplos: "epor ser"; "aellas"; "daPiedade"; "ominino"; “dosertaõ", "mostrandoselhe"; "achandose"; "sesegue".

4. A pontuação original será rigorosamente mantida. No caso de espaço maior intervalar deixado pelo escriba, será marca-do [espaço]. Exemplo: "que podem perjudicar [espaço] Osdias passaõ eninguem comparece”.

5. A acentuação original será rigorosamente mantida, não se permitindo qualquer alteração. Exemplos: "aRepublica"; docommercio ; "edemarcando tambem lugar" ; "Rey D. Jose” ; oRio Pirahý ; "oexercicio"; "que hé munto conveniente".

6. Será respeitado o emprego de maiúsculas e minúsculas como se apresentam no original. No caso de alguma variação física dos sinais gráficos resultar de fatores cursivos, não será con-siderada relevante. Assim, a comparação do traçado da mes-ma letra deve propiciar a melhor solução.

7. Eventuais erros do escriba ou do copista serão remetidos para nota de rodapé, onde se deixará registrada a lição por sua respectiva correção. Exemplo: "nota 1. Pirassocunda por Pirassonunga; "nota 2. deligoncia por deligencia"; "nota 3. adverdinto por advertindo".

8. Inserções do escriba ou do copista na entrelinha ou nas mar-gens superior, laterais ou inferior entrarão na edição entre os sinais $<>$, na localização indicada. Exemplo: <fica definido que olugar convencionado é acasa depedro nolargo damatriz $>$.

9. Supressões feitas pelo escriba ou pelo copista no original serão tachadas. Exemplo: todos ninguen dospresentes assignaron"; "sahiram sahiram aspressas para oadro". No caso de repeti-ção que o escriba ou o copista não suprimiu, passa a ser suprimida pelo editor que a coloca entre colchetes duplos. Exemplo: "fugi[[gi]]ram correndo [[correndo]] emdireçaõ opaço".

10. Intervenções de terceiros no documento original devem apa-recer no final do documento informando-se a localização.

11. Intervenções do editor hão de ser raríssimas, permitindo-se apenas em caso de extrema necessidade, desde que elucidativas a ponto de não deixarem margem a dúvida. Quando ocorrerem, devem vir entre colchetes. Exemplo: "naõ deixe passar neste [registo] de Areas".

12. Letra ou palavra não legível por deterioração justificam intervenção do editor na forma do item anterior, com a indicação entre colchetes: [ilegível].

13. Trecho de maior extensão não legível por deterioração rece-berá a indicação [corroídas \pm 5 linhas]. Se for o caso de trecho riscado ou inteiramente anulado por 
borrão ou pa-pel colado em cima, será registrada a informação pertinen-te entre colchetes e sublinhada.

14. A divisão das linhas do documento original será preserva-da, ao longo do texto, na edição, pela marca de uma barra vertical: | entre as linhas. A mudança de fólio receberá a marcação com o respectivo número na seqüência de duas barras verticais: || 1v. || 2r. || 2v. || 3r. ||

15. Na edição, as linhas serão numeradas de cinco em cinco. Essa numeração será encontrada à margem direita da mancha, à esquerda do leitor. Será feita de maneira contínua por documento.

16. As assinaturas simples ou as rubricas serão sublinhadas. Os sinais públicos serão indicados entre colchetes. Exemplos: assinatura simples: Bernardo Jose de Lorena; sinal público: [Bernardo Jose de Lorena].

Segue exemplo de edição semidiplomática de manuscrito do século XVIII:

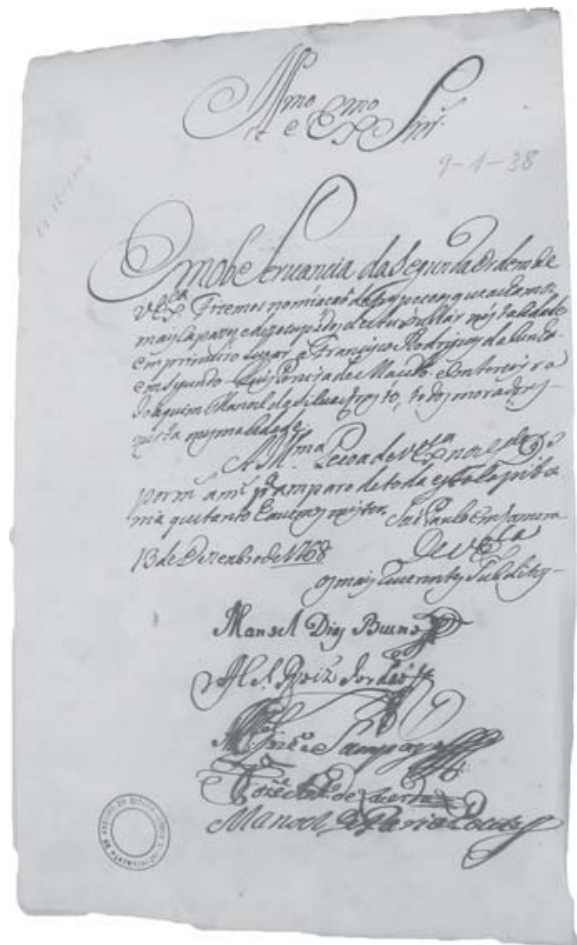

Figura 7 - “ manuscrito datado de 13 de dezembro de 1768.

4 Como a edição está justalinear às imagens dos manuscritos, não será respeitada a marcação com uma barra vertical para indicar a mudança de linha.

5 Não foi seguido o tópico 14 das normas para que a lição pudesse ser melhor comparada com o manuscrito. Esse documento encontra-se no Arquivo do Estado de São Paulo. 
Illustrissimo e Excellentissimo Senhor

Em obSeruançia da SegundaOrdem de

VossaExcellencia Fizemos nomiaçaõ detres peçoas que açhamoz

mais Capazes edezocupados de Aux[u]liar nestaCidade

5 em primeiro Lugar aFrancisco Rodrigues daCunha

emSegundo Luis Pereira deMaçedo eemterceyro

IoaquimManoel daSiluaCrasto, todos moradores -

nesta mesmaCidade

A Illustrissima Pecoa deVossaExcellencia nosguardeDeus

10 pormuitos annos para amparo detoda estaCapita

nia quetanto hauemos mister.

São Paulo emCamera

13 deDezenbrode1768

DeVossaExcelencia

Os mais reuerentes Subditos -

Manoel Dias Bueno

15

[Manoel] Rodriguez Iordaõ

Manoel jozê eSampaio

JozêAntonio deLacerda

Manoel DeFaria Couto

Publicado recentemente, o livro de Massini-Cagliari (2007), Cancioneiros Medievais Galego-Portugueses, traz importantíssima colaboração para a área Filológica, especificamente, a respeito da principal preocupação deste artigo, a fidedignidade dos trabalhos de edição. A autora traz uma coletânea de 13 cantigas medievais profanas, com o cuidado de apresentar exemplos de diversos tipos de edição de cada uma delas, desde a fac-similada, passando pela diplomática e semidiplomática até a crítica. Como afirma Maria do Amparo Tavares Maleval, no prefácio da obra (p. xi-xii), "dessa forma, Gladis MassiniCagliari nos oferece um rigoroso corpus de cantigas, sobre as quais as reflexões de cunho histórico, gramatical, lingüístico ou literário poderão processar-se de forma mais conscienciosa, uma vez que assentadas em bases mais sólidas".

Além de informações acerca dos gêneros poéticos em que se enquadram as cantigas, amor, amigo, escárnio e maldizer, das respectivas fontes localizadas até o momento e dos seus autores, e das características dos diversos tipos de edição, fac-similada, diplomática, semidiplomática e crítica, essa obra, como afirma a própria autora (p.xx), tem como diferencial a apresentação de algumas das diversas edições que uma mesma cantiga recebeu, ao longo do tempo, acompanhada do seu cotejo com a reprodução fotográfica dos manuscritos originais. 
Nesse livro, por exemplo, a cantiga de Nunes Fernandes Torneol, conhecida como Pois naci nunca vi amor, é apresentada em edição fac-similar em duas versões, uma pertencente ao Cancioneiro da Ajuda, fólio 117, outra ao Cancioneiro da Biblioteca Nacional de Lisboa, página 110. Na versão diplomática realizada por Carter (1941), com base na primeira, como a própria autora afirma (2007, p. 71), comprova-se a sua fidelidade ao texto. Já na versão semidiplomática, realizada por Machado \& Machado (1949), tal fato não se verifica, pois as abreviaturas são desenvolvidas sem deixar claro ao leitor os acréscimos feitos, há substituição de maiúsculas por minúsculas e o inverso e introdução de pontuação de acordo com a interpretação dos editores. Na edição crítica de Michaêlis de Vasconcelos (1904, p.168-169), intervindo de acordo com a sua interpretação na busca de estabelecer o texto, segundo Massini-Cagliari (2007, p.76), a pesquisadora adota uma versão às vezes mais próxima do Cancioneiro da Ajuda, às vezes do Cancioneiro da Biblioteca Nacional de Lisboa.

Ao cotejar as cantigas com as respectivas edições, Massini-Cagliari apresenta os critérios utilizados pelos editores e comenta a forma de apresentação de cada edição. Por um lado, à medida que cumpre seu objetivo, o processo de transmissão do texto e a sua corrupção tornam-se evidentes ao leitor; por outro, constata-se o que se afirmou até o momento em relação à escolha de critérios de edição de acordo com o objetivo do trabalho e a consequente intervenção do editor quando a preocupação literária predomina sobre a linguística.

\section{A importância da utilização de critérios de leitura}

No patamar em que se encontram os trabalhos filológicos com vistas à produção de lições fidedignas para estudos de língua escrita, não há dúvida de que as normas utilizadas devam conservar as características linguísticas dos diversos documentos, como é o caso dos produzidos nos séculos XVI, XVII, XVIII e XIX. Essa certeza associada à ideia de que, por tratar-se de manuscritos modernos, o tipo de letra empregado não traria dificuldade de leitura tem motivado muitas pessoas a se aventurar como editores de documentos.

Das normas de transcrição constam os critérios respeitados na edição de manuscritos em relação à atitude do editor perante o documento e à forma pela qual apresentará o resultado de seu trabalho. Embora muitas delas tenham como aspecto norteador uma transcrição conservadora, tal postura não exime o editor de cometer determinados deslizes. Tanto quem copia um manuscrito, quanto quem edita, está sujeito a algum tipo de lapso, mesmo até os mais atentos. 
O interesse por manuscritos coloniais e imperiais e o crescente aumento de grupos de pesquisa de diversas universidades que trabalham com esse tipo de documentação, já citados anteriormente, ao mesmo tempo em que representa um avanço para os estudos da História da Língua Portuguesa e da Lingüística Histórica, traz também uma preocupação quanto à fidedignidade das edições produzidas. Nos trabalhos de edição realizados ultimamente, pouco se fala em Paleografia, nem das dificuldades enfrentadas durante essa tarefa. Passa-se a impressão de que nunca foi tão fácil editar documentos.

Não se exige de todo editor uma classificação da escrita com que se trabalha sob o ponto de vista paleográfico, o que não seria de todo ruim, pois ainda não há classificação que dê conta das características da escrita do Brasil da colônia e do império; porém um conhecimento de suas particularidades a fim de que sua leitura não esteja propicia a oscilações. Risco minimizado ao se realizar esse tipo de trabalho com base em critérios de leitura.

Quem lida com os manuscritos produzidos durante a colônia e o império conhece muito bem as dificuldades de leitura de certos manuscritos causadas, principalmente, pelas particularidades da escrita de seus escribas. A semelhança entre algumas letras e o seu uso em contextos parecidos são exemplos de empecilhos que podem causar erros de leitura. Para evitar tais prejuízos, além de normas de transcrição, o editor necessita seguir uma metodologia de leitura baseada em critérios bem elaborados, para o reconhecimento e a identificação dos caracteres, ampliando, assim, o conjunto de mecanismos à sua disposição para a preparação de lições fidedignas.

Veja-se, por exemplo, a ocorrência das letras $<_{\mathrm{s}}>\mathrm{e}<\mathrm{z}>$ em manuscritos do século XVIII. Com várias formas, ambas são utilizadas de acordo com o conhecimento de língua dos escribas da época, pautado pelo uso que era costume entre seus pares. Embora não refletisse em total discrepância ortográfica, em muitos casos, não apareciam em contextos coincidentes com o uso preconizado.

Exemplos de $<$ s $>$ selecionados em manuscritos do XVIII: 


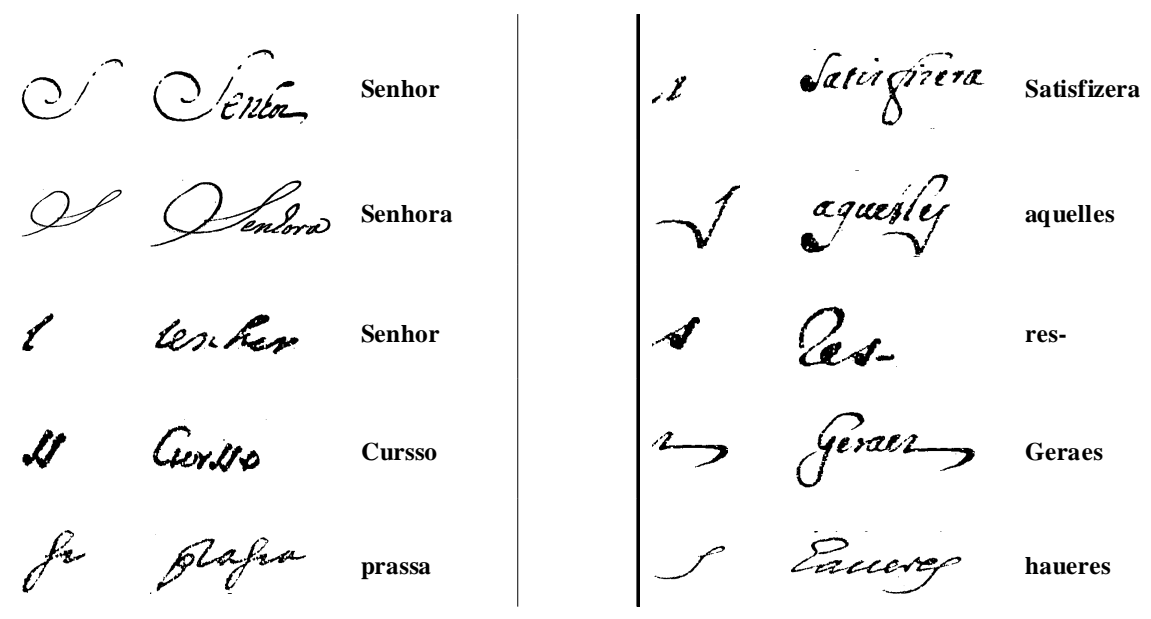

Tabelas 1 e 2 “ Exemplos de $<z>$ selecionados em manuscritos do XVIII.

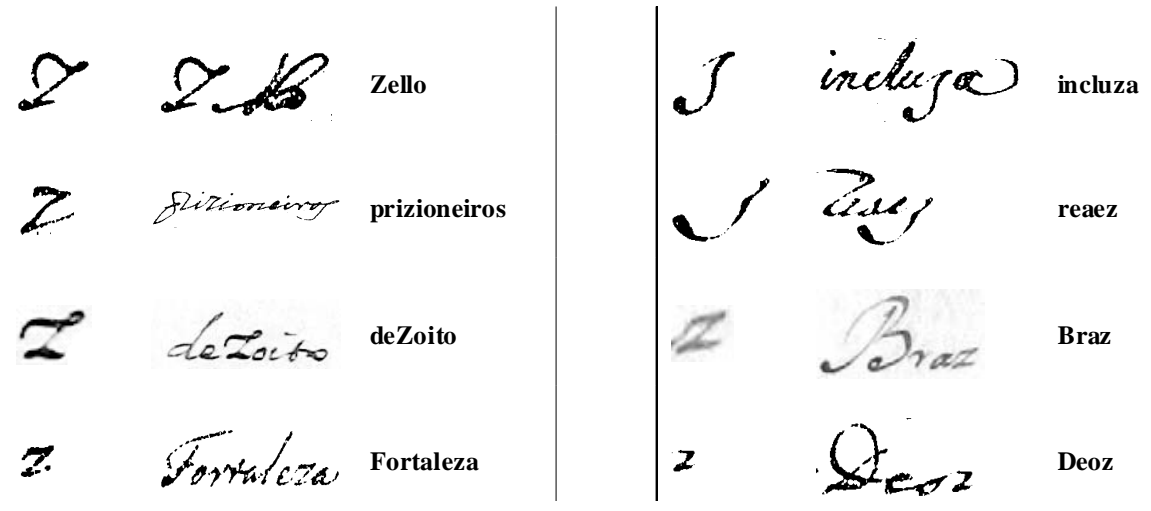

Tabelas 3 e 4 “ Exemplos de $<\mathrm{z}>$ selecionados em manuscritos do XVIII.

As ocorrências das duas letras listadas acima não trazem dificuldade de leitura a um pesquisador experiente, pois são caracteres muito correntes em manuscritos do XVIII. No entanto, há variantes que, em consequência da rapidez da escrita dos escribas, de seu nível de habilidade e até mesmo do contexto em que são utilizadas, perdem as características que se distinguem, exigindo cautela do editor ao transcrevê-las. Como podem ser observadas pelos exemplos seguintes. 


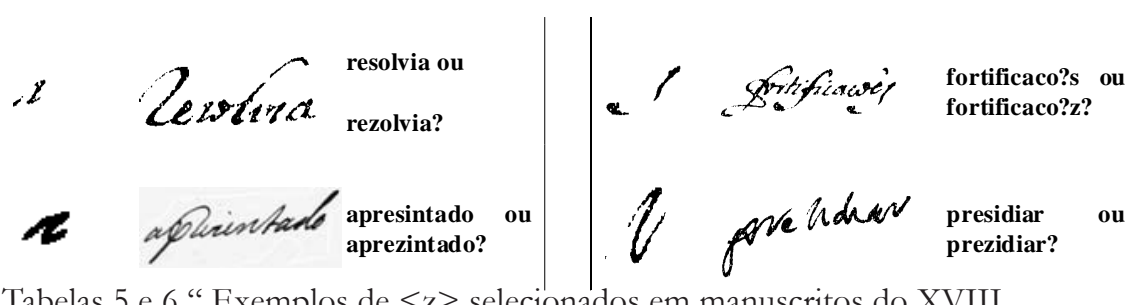

Tabelas 5 e 6 " Exemplos de $<\mathrm{z}>$ selecionados em manuscritos do XVIII.

A dificuldade de distinguir as duas letras não ocorre apenas com $<\mathrm{s}>\mathrm{e}$ $<\mathrm{z}>$, mas com muitas outras, entre elas, $<\mathrm{u}>\mathrm{e}<\mathrm{v}>,<\mathrm{I}>\mathrm{e}<\mathrm{J}>$. A falta de cuidado nessa tarefa pode provocar, além de implicações gráficas, no caso das primeiras, comprometimentos fonéticos, como nos outros exemplos, gerando, assim, problemas de lição e o que Boléo (1946, p.77) chamou de "explicações linguísticas injustificadas".

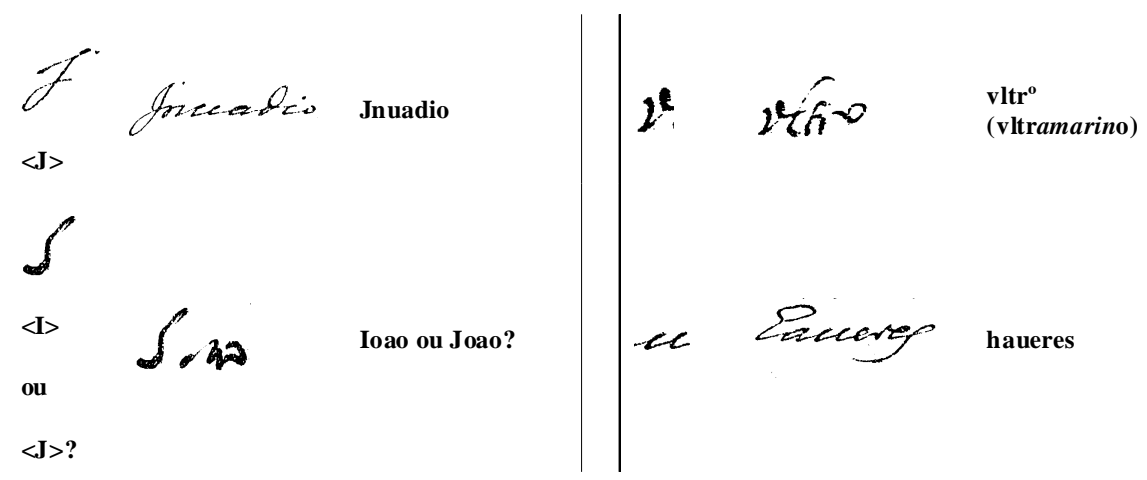

Tabelas 7 e 8 " Exemplos de $<\mathrm{z}>$ selecionados em manuscritos do XVIII.

Como já foi dito, as normas de transcrição direcionam o editor na sua tarefa e dão cientificidade ao seu trabalho, pois deixam claro ao leitor a sua atitude perante o documento e a forma como o resultado será apresentado, porém, por si só, não garantem a fidedignidade da lição. Deve-se sempre lembrar que todo editor está sujeito a lapsos e confusões. Quantas vezes, relendo a própria edição, não se discorda da leitura que é feita? Um grafema antes considerado $<\mathrm{s}>$, por exemplo, mais tarde, com base numa análise mais cuidadosa, pode ser identificado como um $<\mathrm{z}>$, ou uma letra lida como maiúscula, que em outra ocasião passaria por minúscula. Há casos mais graves de erros de leitura que tem como consequência mudança de palavra. Isso ocorre devido à falta de uma metodologia que deve estar à vista do editor a todo o 
momento. A cada nova decisão tomada sobre determinada letra ou a cada dúvida surgida, deve-se confrontá-la com o modelo de seu esquema.

A utilização de critérios de leitura, baseados, principalmente, em uma metodologia paleográfica contribui, consideravelmente, para uma leitura sem oscilação. As tabelas acima, com os exemplos das ocorrências de $<_{\mathrm{s}}>$ e $<\mathrm{Z}>$ e das demais letras, são demonstrações de como isso pode ajudar na eliminação de pendências. A simples separação dos caracteres gráficos de uma palavra e a sua observação isoladamente representam mecanismos que o editor deve utilizar para evitar equívocos durante a leitura.

Os critérios são estabelecidos à medida que se lê o documento. Primeiramente, é preciso que o editor componha o alfabeto da escrita dos manuscritos que estão sendo editados, selecionando cuidadosamente exemplos de cada letra que vão lhe auxiliar no processo de transcrição. De preferência, deve-se organizá-los pela posição onde aparecem na palavra, início, meio ou fim, como se vê no modelo:

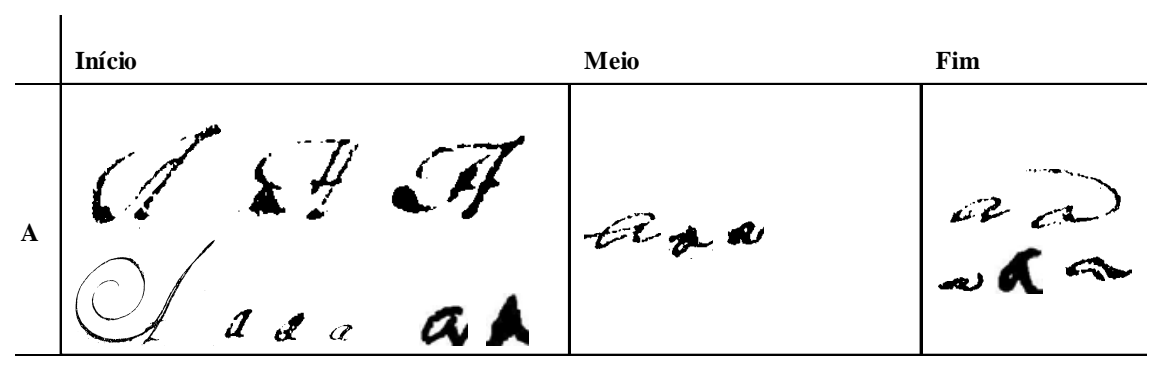

B

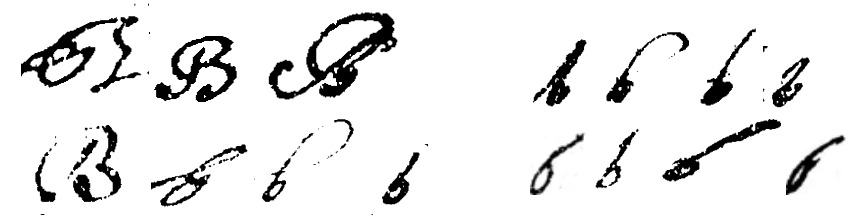

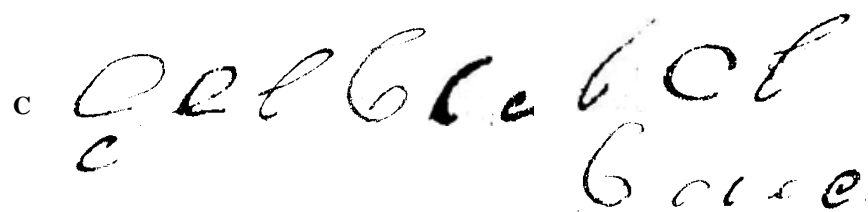

Tabela 9 - "Exemplos de $<\mathrm{z}>$ selecionados em manuscritos do XVIII. 
A seleção das letras possibilita ao editor conhecer as características da escrita em questão, pois ao realizar essa tarefa, obrigatoriamente perfará o caminho do escriba na composição dos caracteres gráficos, acompanhando exatamente a ordem em que os traços foram realizados para compor a sua forma, sem deixar de observar o ângulo gerado pela pena e o suporte, o módulo (suas dimensões quanto à altura, à largura etc.) e o peso de cada letra (traços fortes ou finos de acordo com o instrumento utilizado), ou seja, obrigatoriamente, seguirá a metodologia paleográfica sugerida pelo paleógrafo Jean Mallon (1952) ao realizar estudos de escrita.

Nessa tarefa, todo aspecto que possa gerar dúvida, tanto ao editor, quanto ao leitor, deve ser levado em consideração na elaboração de critérios de leitura. Geralmente, quem edita tem isso em mente, mas não esquematizado, fazendo com que a cada pendência tenha de rememorar e, em muitos casos, (re)elaborar os argumentos que o levaram, segundo ele, a resolver problema semelhante em outro documento, deixando seu trabalho subjetivo e, portanto, nenhum pouco científico.

A representação de maiúsculas e minúsculas e de fronteira, ou não, entre as palavras é assunto que, além de causar dúvida ao editor, é motivo de discordância entre muitos pesquisadores. Por se tratar de questão polêmica, quem edita tem a obrigação de divulgar o critério utilizado para as suas decisões. Assim, o editor coloca à prova seus critérios e o estudioso tem como decidir se tal edição enquadra-se, ou não, em seu objeto de estudo. O quadro abaixo traz alguns casos que justificam essa assertiva.

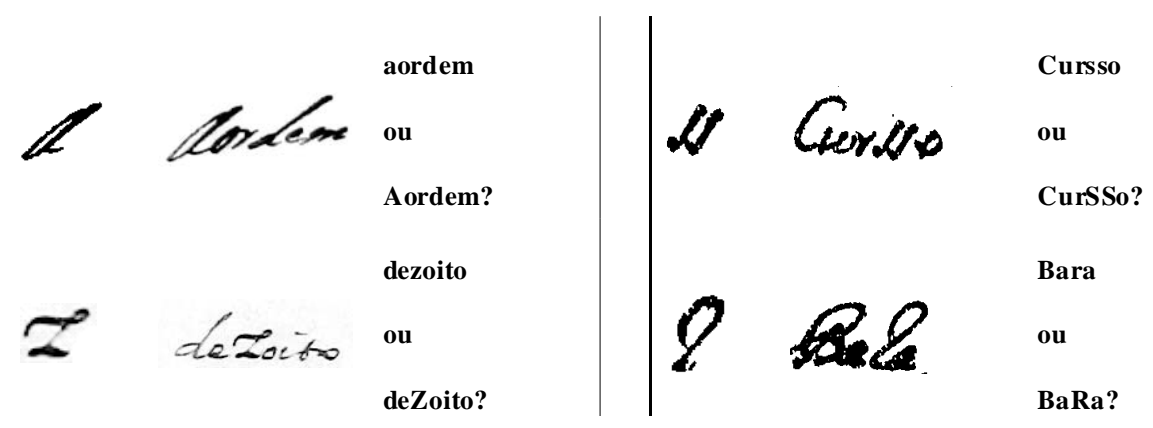

Tabelas 10 e 11 “ Exemplos de $<\mathrm{z}>$ selecionados em manuscritos do XVIII.

\section{Conclusão}

Manuscritos avulsos, produzidos por vários punhos e com um conjunto variado de formas para a mesma letra, impõem ao filólogo um cuidado 
maior ao realizar a sua leitura, o que torna obrigatório para a produção de lições fidedignas o uso de normas de transcrição e o estabelecimento de critérios de leitura. A composição de alfabeto, indicando a posição de cada letra no documento, com a listagem de letras consideradas maiúsculas e minúsculas e com a resolução de pendências enfrentadas durante a leitura, além de evitar oscilações durante a leitura, contribui para a formação de um corpus que possa embasar estudos paleográficos com fins classificatórios da escrita do período da colônia e do império.

Somente por meio da divulgação das normas de transcrição e dos critérios de leitura utilizados na realização da edição dos documentos é possível oferecer ao leitor a possibilidade de verificar com exatidão o caminho percorrido pelo filólogo. Em outros tempos, com outros objetivos, que não os estudos de língua, como foi demonstrado, aceitava-se a intervenção do editor com o intuito de ampliar o alcance de determinada obra. Porém, quando o objetivo não é esse, há a necessidade de se munir de todos os mecanismos possíveis para que não haja oscilações na leitura apresentada.

\section{Bibliografia}

ALLEN, J. (1953) Two old portuguese versions of the life of Saint Alexis - Codices Alcobacenses 36 na 266, sep. De Illinois Studies in Language and Literature, Urbana. Illinois: Teh University of Illinois Press.

BOLEO, M. de P. (1946) Introdução ao estudo da filologia portuguêsa. Lisboa: Revista Portuguesa. CAMBRAIA, C. N. (1997) Subsídios para uma proposta de normas de edição de textos para estudos lingüísticos. In: I Seminário de Filologia e Lingua Portuguesa. I Seminário de Filologia e Língua Portuguesa. São Paulo : Humanitas, v. 1. p. 13-23.

(2001) Subsídios para a fixação de normas de transcrição de textos para estudos lingüísticos - I. In: MATTOS E SILVA, R. V. (org.) Para a bistória do português brasileiro. Vol II: Primeiros estudos. São Paulo: Humanitas, v. II, p. 531-534.

Cambraia, C. N.; CUnHA, A. G. da; MEgale, H. (1999) A carta de Pero Vaz de Caminha. São Paulo: Série Diachronica, 1, Humanitas, p. 23-26.

CARTER, H. (1941) Cancioneiro da Ajuda: Uma Edição Diplomática. Nova Iorque: Modern Language Association of America.

CASTRO, I.; RAMOS, M. A. (1986) Estratégia e táctica de transcrição. In: Critique Textualle Portugaise. Actes du Colloque. Paris: Fondation Calouste Gulbenkian. Centre Cultural Portugais, p. 99-122.

CINTRA, L. F. L. (1951) Cronica geral de espanha de 1344 (edição crítica). Lisboa: Academia Portuguesa da Historia.

CUNHA, C. F. da (1956) O cancioneiro de Martin Codax (edição crítica). Rio de Janeiro: [Departamento de Imprensa Nacional].

LAPA, M. R. (1965) Cantigas d'escarnho e de mal dizer dos cancioneiros medievais galego-portugueses. Vigo: Editorial Galaxia. 
MACHADO, E. P.; MACHADO, J. P. (1949) Cancioneiro da Biblioteca Nacional - antigo Colocci Brancutt. Lisboa: Revista de Portugal.

MASSINI-CAGLIARI, G. (2007) Cancioneiros medievais galego-portugueses: fontes, edições e estrutura. São Paulo: WMF Marins Fonte.

MEGALE, H. (2001) Subsídios para a fixação de normas de transcrição de textos para estudos lingüísticos - II. In: MATTOS E SILVA, R. V. (org.) Para a bistória do português brasileiro. v. II: Primeiros estudos. São Paulo: Humanitas, v. II, p. 535-538.

MELO, G. C. de. (1971) Iniciação à filologia portuguesa. Rio de Janeiro: Academica.

NUNES, J. J. (1926) Cantigas d'amigo dos trovadores galego-portugueses (edição crítica). Coimbra: Imprensa da Universidade.

PICCHIO, L. S. (1979) Licão do texto, filologia e literatura i - idade média. São Paulo: Martins.

SILVA NETO, S. da (1956) Textos medievais portuguêses e seus problemas. Rio de Janeiro: Ministério da Educação e Cultura, Casa de Rui Barbosa.

TOLEDO NETO, S. de A. (2001) Subsídios para a fixação de normas de transcrição de textos para estudos lingǘsticos - III. In: MATTOS E SILVA, R. V. (org.) Para a bistória do português brasileiro: primeiros estudos. São Paulo: Humanitas, v. 2, p. 539-549.

VASCONCELOS, C. M. de (1885) Poesias de Sá de Miranda (edição crítica). Halle: Niemeyer.

(1904) Cancioneiro da Ajuda (edição crítica). Lisboa: Imprensa Nacional - Casa da Moeda, 1990. Reimpressão da edição de Halle (1904).

VASCONCELLOS, J. L. de (1928) Opúsculos. Coimbra: Imprensa da Universidade, v. 1.

ABSTRACT: This article aims to propose a discussion about the importance of the use of criteria for the reading of manuscripts as an indispensable procedure for the production of reliable lessons. They are necessary for the elimination of unsolved questions and, consequently, the scope for a reading without hesitations, because they are essential to the recognition and distinction of graphical characters of each text. The text is divided into two parts. First, philological works and their problems are contextualized, showing, by means of examples of the work of important researchers, changes in the way of editing documents. The second part deals with the importance of the use of criteria for reading and how it is done in practice, by means of examples taken from manuscripts of the eighteenth century.

KEYWORDS: Philology; edition of manuscripts; criteria for reading; history of the Portuguese language. 